\title{
AÇÃO INSTITUCIONAL, CONFIANÇA NA POLÍCIA E LEGITIMIDADE EM SÃO PAULO*
}

\section{André Zanetic}

Núcleo de Estudos da Violência da Universidade de São Paulo (NEV/USP), São Paulo - SP, Brasil. E-mail:andrezanetic@gmail.com

DOI $10.17666 / 329508 / 2017$

\section{Introdução: o problema da confiança e da legitimidade}

A preocupação com a confiança nas instituiçóes públicas e com a construção da legitimidade das instituiçôes democráticas é tema que já está presente há bastante tempo entre pesquisadores de diferentes áreas, em especial entre os sociólogos e

* Este artigo foi desenvolvido no âmbito de uma pesquisa de pós-doutorado realizada no programa "Building democracy daily: human rights, violence and institutional trust" do Núcleo de Estudos da Violência da Universidade de São Paulo - NEV/USP (Cepid-Fapesp). Agradeço ao apoio da Fapesp para a realização deste trabalho. Agradeço também aos pareceristas anônimos da $R B C S$ que muito me ajudaram a refletir sobre este texto, com importantes e enriquecedores comentários e críticas construtivas que me levaram a revisar, aprimorar e compor esta versão final.

Artigo recebido em 30/03/2015

Aprovado em 08/03/2017 cientistas políticos. Nas últimas décadas, autores como Zmerli e Newton (2006), Putnam (1996), Coleman (1988), Granoveter (1985) e muitos outros tem analisado o tema com diferentes matizes, abordando entre seus estudos os fatores que levam a uma ampliação ou diminuição, em alguma medida, da crença na virtude das instituiçóes, bem como as formas como esta crença é construída. Conectado a isso, outro ponto central que tem sido abordado são os impactos que essas crenças podem gerar sobre a capacidade das diferentes instituiçóes em criar e desenvolver adequadamente as políticas públicas que estão sob sua responsabilidade.

O interesse pelo tema ganhou força sobretudo nos anos de 1970 e início da década seguinte, em um contexto internacional de redução da confiança dos cidadãos nas instituiçóes públicas, que emergiu em período subsequente à crise econômica internacional que abalou as estruturas dos Estados de Bem-Estar Social em muitos países. Na busca de interpretaçóes 
sobre esse refluxo na confiança institucional e seus impactos, uma série de correntes teóricas tem sido mobilizada: linhas que enfatizam a forma com que as instituiçóes afetam o comportamento dos atores que interagem no processo político, bem como a forma pelas quais as instituições são moldadas pelo processo histórico; linhas mais voltadas ao contexto em que as instituiçóes operam, com ênfase nas variáveis socioeconômicas ou nas variaçóes culturais; e as linhas que têm enfatizado as características individuais, de cunho mais sociopsicológico.

Ainda que em pequena monta até aqui, o tema da legitimidade tem motivado também estudiosos das dinâmicas criminais, tendo como foco a investigação da conexão entre fatores como os diversos aspectos vinculados às práticas de crimes e violências (incluindo o medo e a sensação de insegurança) e as açôes institucionais colocadas em prática pelos agentes públicos. Com diferentes formulações da legitimidade e da confiança nas instituiçóes, autores como Nivette e Eisner (2013), Roth (2009), Fagan e Piquero (2007), Sunshine e Tyler (2003), Eisner (2001), LaFree (1998), Sampson e Bartusch's (1998), entre outros, tem mostrado importantes conexóes empíricas entre legitimidade política e institucional, confiança, cometimento de crimes, obediência às leis e cooperação com a polícia em diferentes contextos internacionais. Entre as questóes centrais que sustentam essa produção estão alguns temas tradicionais do campo das ciências sociais, como os fatores determinantes da obediência e do reconhecimento das leis e das esferas da autoridade.

Os estudos sobre a confiança e a legitimidade, no que diz respeito às questóes ligadas ao campo da segurança pública, em especial à legitimidade policial, têm sido produzidos em oposição às visóes e, sobretudo, às práticas predominantes na área sobre o tratamento dos problemas relacionados com o crime, que têm sido focalizadas em medidas como a intensificação do aprisionamento e da ostensividade das forças policiais, privilegiando mais as açôes repressivas do que preventivas. Nesse modo de agir, policiais dão excessiva atenção aos resultados relativos ao enfrentamento do crime (contabilizados em flagrantes, prisóes, abordagens e apreensóes diversas) e pouca à qualidade do relacionamento interpessoal com os cidadãos, eventualmente colocando-os também em situação de risco ou de sujeição a arbitrariedades. Essa prática das instituiçóes de justiça criminal no Brasil, em especial das polícias, aproxima-se em grande parte do ideário presente nas teorias dissuasórias do crime, que veem no aumento do custo do crime para ofensores motivados ao cometimento de atos ilegais a estratégia mais efetiva para a resolução dos problemas de segurança pública. Esse aumento do custo do crime, por sua vez, é proveniente de fatores como o aumento da percepção do risco de ser pego, as consequências de ser pego (que envolve, também, o custo relativo ao aumento das penas) e outros fatores, como o grau de dificuldade da efetivação dos crimes.

Segundo a teoria, cada indivíduo realiza escolhas, pautadas exclusivamente pelo cálculo de custo-benefício instrumental diante das opçóes existentes no mercado ilegal, dos riscos relativos à chance de ser preso, das puniçóes existentes e das próprias opçôes do mercado legal que também apresenta oportunidades (Ehrlich, 1996; Becker, 1968). A estratégia se efetivaria à medida que o cálculo racional desses riscos dissuadisse potenciais autores de crimes de levar à cabo suas ações criminosas. Na prática, o que se vê no Brasil é uma exacerbação do que é descrito pelas teorias dissuasórias, com a ação policial sendo marcada náo apenas pelo uso dos instrumentos legais de repressão, mas também, e frequentemente, pela arbitrariedade e pelo abuso da violência.

Não obstante a necessidade do desenvolvimento das atividades policiais (e dos demais organismos do sistema de justiça criminal), entre as quais as tarefas repressivas e de efetuação de aprisionamentos, junto com funçóes preventivas, ser parte fundamental do desenvolvimento das açôes de segurança pública, os estudos desenvolvidos no campo da legitimidade têm apontado limites às práticas dissuasórias, focalizadas em aspectos instrumentais. Esses estudos vêm demonstrando, por meio de pesquisas empíricas, que a aposta na construção da legitimidade das instituições e dos agentes públicos, e do consequente fortalecimento de uma obediência normativa (em vez de instrumental) pautada no autocontrole dos cidadãos, pode ser mais eficaz e menos custosa do que a centralização dos esforços nas práticas dissuasórias. A própria aplicação dessas práticas deve ser desempenhada de forma a favorecer a legitimidade das açóes e das instituiçóes perante a população. 
Evidentemente, o aprimoramento desse autocontrole não é tarefa que cabe somente à polícia e aos setores de segurança pública. Trata-se de questão muito mais abrangente. As polícias, no entanto, exercem uma função muito importante nesse processo, tanto em relação à percepção específica dada pela experiência do contato direto com os cidadáos, como em relação à percepção difusa, construída por valores mais gerais acerca da instituição. Para a polícia, esse autocontrole dos cidadãos é fundamental, uma vez que ela não tem condiçóes de estar em todos os lugares ao mesmo tempo.

$\mathrm{O}$ presente artigo investiga particularmente o universo das instituiçóes policiais e suas relaçóes com os cidadãos: a construção das dimensões de confiança e legitimidade, com base em percepções e nas relações diretas dos cidadãos com as instituiçôes públicas e seus agentes. Analisa-se, assim, a hipótese segundo a qual a percepção cidadã de justeza procedimental (procedural justice) das instituições é capaz de fomentar e amplificar a confiança e a legitimidade que os cidadáos possuem acerca das polícias de forma mais importante que a eficácia policial e outros aspectos instrumentais. São também analisadas outras variáveis e aspectos estruturais e contextuais que possuem impacto relevante sobre as dimensóes observadas. Na primeira parte, investigamos a construção da noção de legitimidade e do conceito de justeza procedimental. A seguir, na parte 2, fazemos uma breve apresentação do contexto brasileiro com relação ao cenário da segurança pública. $\mathrm{Na}$ parte 3, apresentamos as características do estudo, a metodologia e os dados utilizados, além da forma como foram analisados. $\mathrm{Na}$ parte 4 são apresentados os resultados da análise, identificando-se e problematizando-se os diversos fatores que causam impacto na construção da confiança e da legitimidade. Nas consideraçôes finais, discutimos os resultados obtidos, apontando novas perspectivas para a análise do tema.

\section{Os avanços da justeza procedimental e limitaçóes}

No campo da segurança pública, justiça e violência, uma mudança importante relativa ao estudo dos aspectos que estão por trás da obediência às leis e da ocorrência (ou não ocorrência) de ofensas cri- minais ocorreu, a partir do final dos anos de 1980, com o aparecimento dos trabalhos do criminólogo norte-americano Tom Tyler. Junto com outros pesquisadores, esse autor passou a problematizar algumas das teorias criminológicas tradicionais sobre os fatores determinantes dessas ações, bem como as políticas públicas postas em prática nessa área. Fundamentando-se em estudos empíricos, eles questionaram a eficácia das estratégias de controle do crime pautadas apenas no uso da coerção e na perspectiva de punição, que consequentemente gerou também o aumento dos custos dos mecanismos dos sistemas de proteção responsáveis pela efetiva manutenção de seu funcionamento. Em contrapartida, eles argumentam (pautados também por extensa pesquisa empírica) que o que move de forma muito mais efetiva os indivíduos em direção ao cumprimento das regras da sociedade é a sua própria autorregulação. Ou seja, a não ocorrência da desobediência e da prática de crimes relaciona-se diretamente com aspectos normativos internalizados, que impelem os indivíduos a não transgredirem, em oposição à primazia da concepção de que essas condutas seriam resultado das estratégias focadas na repressão e na punição que ocorrem como resposta a essas açóes.

A conduta autorregulada desenvolve-se no indivíduo com base em incentivos motivacionais, identidades e valores compartilhados, os quais representam razóes e sentidos importantes para a internalização de noçóes como o respeito às instituiçóes e às regras socialmente estabelecidas. Esse reconhecimento das instituições é a característica central da legitimidade, que pode ser compreendida como o direito das autoridades de governar com o consentimento dos cidadãos.

Mas sob quais condiçóes se encontram os membros de uma sociedade obrigados a cumprir suas leis? Como são construídas as condutas individuais? A questão da legitimidade já estava presente nos escritos dos principais filósofos políticos do Estado moderno, em especial Thomas Hobbes, John Locke e Jean-Jacques Rousseau, estendendo-se também a autores de diferentes linhagens intelectuais, como Georg Wilhelm Friedrich Hegel e Max Weber, como tema central para a compreensão das relações de poder e da formação dos agrupamentos 
políticos. Hobbes, Locke e Rousseau entendem que a legitimidade da comunidade política está baseada no consenso de seus membros, a partir do pacto que funda essa coletividade. Para Locke, por exemplo, a obrigaçáo de cumprir as leis só existe se a autoridade estiver baseada na legitimidade, a qual se constitui, segundo essa visão, como a base para a criação da sociedade civil.

Há diferentes formas pelas quais a legitimidade das leis e das instituiçóes pode ser compreendida. Para o teórico social David Beetham (1991), há uma diferença marcante entre o conceito normativo de legitimidade dos filósofos políticos, delineados pela configuração de padróes morais e abstratos como critério independente de legitimidade, e o conceito empiricista weberiano da "crença na legitimidade". O que é considerado legítimo para os filósofos é o que pode ser justificado moralmente ou tido como legalmente correto, engendrando uma justificabilidade moral das relaçóes de poder (Beetham, 1991; Coicaud, 2002).

A visão weberiana sobre a legitimidade é radicalmente distinta. Weber não está ocupado em "resolver disputas legais ou dilemas morais sobre o poder", mas sim "em identificar as consequências empíricas da legitimidade para o caráter das relaçóes de poder, nas diferentes formas em que elas estão organizadas" (Beetham, 1991, p. 5, tradução nossa) e também se, e em que extensão, os governantes podem de fato contar com o apoio e a obediência de seus subordinados. Por essas características, que marcam diferenças importantes em relação ao conceito de legitimidade dos filósofos políticos e permitem analisar os impactos das diferenças de contexto e mudanças sociais diversas sobre a legitimidade e as relaçóes de poder, é que muitos cientistas sociais teriam passado a seguir a definiçấo de legitimidade de Weber, caracterizada como a crença na legitimidade (belief in legitimacy) das autoridades e das instituiçóes. Passaram a entender, assim, as relaçōes de poder como legítimas quando aqueles que nelas estáo envolvidas, tanto os subordinados como os dominantes, acreditam na legitimidade dessas relaçôes (Weber, 1968). Para Weber não importa, como seria a preocupação dos filósofos, fazer um julgamento moral para saber se uma relação de poder é legítima. O que importa é a crença dos indivíduos nessa legitimidade.
Beetham tem a abordagem empiricista como principal estratégia de análise em seu trabalho sobre a legitimação do poder. Não porque náo dê importância aos dilemas morais dos indivíduos com relação ao cumprimento das obrigaçóes ou com suas relações de poder - muito pelo contrário, essa dimensão normativa da legitimidade identificada na análise dos filósofos políticos se mantém como uma dimensão importante na sua construçáo conceitual da legitimidade, como veremos adiante -, mas sim porque seu principal objetivo é compreender as causas e as consequências da desobediência. Entretanto, o autor nega veementemente a abordagem empírica weberiana sobre o tema. Beetham identifica uma série de falhas nessa abordagem, decorrentes dos problemas da própria definição do conceito (belief in legitimacy), à qual Beetham se opõe afirmando que "uma dada relação de poder não é legítima porque as pessoas acreditam em sua legitimidade, mas porque essa relação de poder pode ser justificada em termos de suas crenças" (Beetham, 1991, p. 11, tradução nossa).

Para ele, o conceito de legitimidade significa uma avaliação normativa de uma instituição ou de um regime político, o que envolve a "correçáo de seus procedimentos", muitas vezes com base legal, "a justificação de suas decisões e a forma como são tratados os governados" (Idem, p. 10). Em sua análise, o conceito weberiano de legitimidade não representa uma avaliação acerca de uma determinada instância de poder. Weber desconsidera os aspectos da legitimidade que têm pouco a ver com crenças de uma forma geral, porém a congruência entre os valores, as expectativas e o conhecimentos de cada indivíduo, nessa visão, deveriam necessariamente ir além do plano da simples crença. Ainda que Weber realize uma exploração abrangente sobre os fundamentos da crença na análise de seus tipos de dominação, o problema para Beetham reside no fato de que a noção de crença na legitimidade está pautada em uma leitura incompleta das relaçóes entre crença e legitimidade, impedindo a compreensão das dimensōes que fundamentam essa legitimidade.

A partir dessa análise crítica da concepção weberiana, o autor constrói as dimensōes que constituem o conceito por meio de sua justificação com base nas crenças individuais: o consentimento (reco- 
nhecimento, expresso através de ações, do direito ao exercício do poder pelas autoridades), legalidade (validade, de acordo com regras sociais e normas legais, da aquisição e do exercício do poder) e valores compartilhados (convergência e justificação em termos de crenças e valores, entre as autoridades e os que a elas estão submetidos, em termos das regras que regem as relaçóes de poder). Essas dimensôes não são, na visão de Beetham, alternativas, todas contribuem para a legitimidade. Em cada contexto, entretanto, essas dimensóes irão se manifestar em diferentes níveis, o que faz com que a legitimidade não seja uma questão de "oito-ou-oitenta" (ou existe, ou não existe).

Nessa visão, a legitimidade das relações de poder, ou qualquer outra forma de legitimidade, é sempre relativa ao contexto em que se insere o objeto da legitimidade, em vez de ser "absoluta, ideal ou abstrata". No entanto, ainda que esses critérios de legitimidade sejam diferentes daqueles comuns aos filósofos políticos, tanto estes como os cientistas sociais trabalham necessariamente com a mesma noção de critérios de justificabilidade normativa dessas relações.

Tyler tem na concepção de Beetham a base teórica de seu conceito de legitimidade, cuja noçáo se encontra na dimensão mais importante para a existência da autorregulação dos indivíduos em relação às regras sociais. Por meio de estudos empíricos sobre a legitimidade no universo institucional específico das polícias, entretanto, Tyler aprofundou a análise sobre os fatores que determinam a legitimação ou deslegitimação das autoridades, e avançou também na compreensão do impacto da legitimidade sobre a obediência e a cooperação com as autoridades. Esse senso de legitimidade, por sua vez, no que tange ao universo das práticas criminais, estaria ligado diretamente à atuaçáo do sistema de justiça criminal, em especial na figura e no papel representado por seus operadores nas suas tarefas de gerenciamento dos problemas de justiça, segurança e resolução de conflitos.

A forma e a adequaçáo dos procedimentos adotados (transparência, capacidade de ouvir os envolvidos e levá-los em consideração), a qualidade das decisóes tomadas (qualidade técnica e cumprimento das regras) e a qualidade de tratamento in- terpessoal (respeito, tratamento justo) configuram-se como aspectos reguladores centrais da atuação institucional. Essas características resumem o que esses autores entendem por justeza procedimental (Tyler e Jackson, 2013; Tankebe, 2013; Sunshine e Tyler, 2003; Tyler, 1990). Nessa visão, havendo justeza procedimental, os cidadãos tenderão a conferir legitimidade às autoridades legais e às regras sociais e a internalizar satisfatoriamente as condutas que os manterâo mais distantes de incorrer em desvios e transgressóes criminais. Cabe também destacar que as análises acerca dos agentes públicos e seu papel na relação com os cidadãos, embora digam respeito a atores de diferentes níveis e patentes, dão atenção especial aos funcionários dos escalóes mais baixos, que possuem uma interface muito significativa com a população e, consequentemente, exercem grande influência na forma como a política pública é executada. ${ }^{1}$

Para além dos resultados institucionais com relação aos problemas criminais existentes, portanto, pode-se aventar também como tendo importância crucial para a percepção dos cidadáos quanto ao funcionamento dessas instituições - bem como para o nível de confiança que a elas pode ser creditada - as formas como os agentes estatais se relacionam com o público e demonstram, na prática, estarem procurando resolver os problemas, na linha dos estudos iniciados por Tyler. Características como imparcialidade, lisura e presteza seriam, nesse sentido, aspectos significativos na forma como os cidadãos irão avaliar as instituiçôes. Torna-se claro, neste enquadramento, o papel que o desempenho institucional pode ter para o fortalecimento da legitimidade das instituições e para sua eficiência quanto ao cumprimento das obrigaçóes.

Cabe dizer, em relação à legitimidade e à confiança, que essas duas esferas correspondem a dimensões distintas, ainda que haja uma intersecção clara entre elas. Enquanto a legitimidade liga-se ao reconhecimento do direito consentido de governar, a confiança institucional, por outro lado, relaciona-se muito mais com a expectativa (normativa) futura acerca das açóes institucionais, comparadas à experiência prática vivida nessas instituições (Moisés, 2008). Nesse sentido, ao conferir confiança à uma instituição, os indivíduos estão operando, simulta- 
neamente, uma avaliação racional e normativa acerca dessa instituição.

Ainda que as teorias da justeza procedimental tenham representado enormes avanços no campo da compreensão das dinâmicas vinculadas às transgressóes e à obediência às leis e seus determinantes e ainda que essas teorias tenham de fato apresentado resultados robustos que corroboram esses avanços - apontando também para a perspectiva de aprimoramento de políticas públicas voltadas à redução das ofensas criminais e seu tratamento pelos agentes do sistema de justiça e segurança -, críticas importantes surgiram na última década dirigidas a insuficiências dessa abordagem e a necessidade de se avançar em outros pontos relevantes. ${ }^{2}$

Em trabalho recente realizado sobre o tema, Nivette e Eisner (2013) apontaram relevantes questôes metodológicas a serem absorvidas nesse tipo de estudo. Os autores, que haviam analisado os impactos provenientes da baixa legitimidade (ou, neste caso, da baixa crença nas leis) sobre os crimes, chamaram a atenção para a necessidade de se estudar o problema longitudinalmente e em profundidade para melhor se aferir a direção da causalidade entre as características observadas. Apesar da crítica, deve-se destacar que foram realizados esforços para analisar a teoria da justeza procedimental e da legitimidade de forma longitudinal. Tyler e Fagan (2008), por exemplo, desenvolveram em Nova York um estudo de painel, com duas amostras em 2002 e 2004, em que encontraram, entre outros fatores, que a presença da justeza procedimental observada na primeira onda da aplicação do survey estava altamente correlacionada com a legitimidade e com a justeza procedimental na segunda onda, demonstrando haver um componente importante de percepção prévia da ação das polícias a ser considerado na propensão a conferir legitimidade à instituição.

Outros fatores que também merecem atenção são a conexão entre as análises de níveis micro e macro e a operacionalização do conceito de legitimidade. As análises de nível macro focalizam as variações temporais e espaciais (entre naçôes, regiōes e vizinhanças) nos crimes e nas violências; as de nível micro, os comportamentos individuais em relação às percepções sobre a legitimidade das instituições (Nivette e Eisner, 2013). Até o momento, foram poucas as pesquisas sobre a justeza procedimental em outros contextos que não o britânico e o norte-americano, o que impede a realização de comparaçóes com realidades socioculturais significativamente distintas. Dentre essas, destaca-se o estudo realizado por Justice Tankebe (2009) em Gana. Em um contexto mais próximo ao brasileiro, a análise demostrou que, ao contrário dos resultados obtidos pela maior parte das pesquisas na área, os aspectos instrumentais relacionados com a eficácia policial são os mais relevantes na determinação da cooperação com a polícia entre os ganeses, contestando empiricamente os achados da teoria da justeza procedimental naquele contexto. $\mathrm{O}$ autor credita esses resultados à própria construção histórica da polícia do país, marcada pelo colonialismo e pela frágil performance policial, o que gerou grande déficit de legitimação das polícias.

\section{O cenário brasileiro}

Ao ampliarmos essa discussão para diferentes contextos, observamos a presença de práticas de violência e má conduta policial que adquirem contornos especialmente fortes em determinados países. No Brasil, por exemplo, que concentra altíssimas taxas de violência policial, ${ }^{3}$ políticas que exaltam a violência policial são comumente postas em prática por serem populares, com uma seletividade direcionada quase que exclusivamente contra os mais pobres e vulneráveis (Chevigny, 2000, p. 66). Nesse sentido, parece claro que o contexto social e o contato direto com agentes de segurança são aspectos cruciais na determinação da relação entre performance institucional, confiança nas polícias e legitimidade. ${ }^{4}$ Estudos recentes no Brasil mostram a importância de se analisar conjuntamente essas variáveis, associadas a aspectos do desempenho institucional, como violência e abuso policial, ineficácia no controle e na resolução de problemas criminais, tratamento desrespeitoso aos cidadãos, entre outros (Oliveira Júnior, 2011; Lopes, 2008; Soares, 2000).

Vale ressaltar, quanto a isso, algumas peculiaridades do cenário nacional. O Brasil teve o mais amplo e longevo processo escravagista durante a colo- 
nização europeia. Foi o último país das Américas a abolir a escravidão, que durou praticamente quatro séculos, encerrando-se em 1888. Após a abolição, não se previu nenhum processo efetivo de inserção no mundo dos direitos e da cidadania dessa enorme população até então exclusa, que nunca foi preparada para fazer parte do mercado de trabalho para o qual deveria então se direcionar e se adequar. Nas condiçóes em que foram colocados, não seria demais afirmar que os negros estavam mais integrados no sistema escravista que na sua nova condição de trabalhadores livres (Ianni, [1962] 1988). Não há dúvida do impacto que todo esse processo teve na sociedade e na cultura brasileira.

As agruras vividas pela população negra no Brasil, tanto no período da escravidão, sustentada por sua relação íntima com a violência, como nos anos subsequentes à abolição, em que transparece o tortuoso processo de construção de sua cidadania incompleta e a manutençáo da cor como forte marcador da diferenciação social, são descritas e analisadas por diversos pesquisadores, sobretudo da segunda metade do século XX (Costa, [1966] 1999; Alencastro, 1997; Ribeiro, 1996; Ianni, [1962] 1988; entre outros).

Essa herança do escravagismo e das relaçóes patrimonialistas marcou profundamente a relação da população brasileira com as autoridades, em um país que viveu o século XX se equilibrando instavelmente em meio a transiçóes entre regimes autoritários "legalizados" (de 1937-1945 e de 1964-1985) e regimes democráticos, embora estes últimos fossem também inundados pela presença de um autoritarismo "efetivo", com a presença dissimulada de um controle social das classes populares, ancorado nas práticas da repressão política e da violência física ilegal (Pinheiro, 1991). É assim que as práticas e os métodos de repressão policial comuns ao último período militar, que oficialmente se encerrou em 1985, permaneceram na transição subsequente, confirmando-se na Constituição de 1988, que praticamente não mexeu na organização das instituiçóes de segurança pública do período ditatorial.

A repressão do Estado, que está presente também na sociedade, perpassa os diferentes regimes e os períodos de transição. Sua permanência é garantida não só pelas relaçóes de poder na esfera macro- política, como também é legitimada por camadas substantivas no interior da sociedade brasileira, compostas até mesmo por parcelas da população que são alvo constante da violência ilegal cometida por agentes do estado.

A questão da segurança pública no Brasil configura hoje um quadro dramático, com uma estatística que aponta para mais de 50 mil mortes violentas intencionais por ano (homicídio, latrocínios, lesôes corporais seguidas de morte e mortes decorrentes de intervençóes policiais). Em 2015, de acordo com os dados do Anuário Brasileiro de Segurança Pública (2016), o Brasil foi o país que teve o maior número absoluto de homicídios, 54.023 (com um total de 58.492 mortes violentas intencionais). Em termos proporcionais, o país estava, nesse ano, entre os dez mais violentos do mundo. A gravidade da situação, evidentemente, atinge o dia a dia dos cidadãos e delineia sua visão sobre a capacidade do meio institucional diretamente envolvido com o tema (a polícia e a justiça) de resolver os problemas, o que pode abalar a própria crença das pessoas nas instituiçôes de maneira geral.

Também chamam atenção, nesse cenário, os índices elevados da impunidade e, com isso, a redução da certeza de que criminosos serão punidos, tendo em vista o descarte da aplicação das leis penais em alguma das fases do fluxo do sistema de justiça criminal (Ribeiro e Silva, 2010; Adorno e Pasinato, 2010, 2007). A capacidade de absorver a demanda e a resposta positiva nos trabalhos efetivados para a soluçáo de crimes são fatores essenciais para o bom funcionamento das instituiçóes de justiça e segurança e para sua própria legitimidade; curiosamente, eles estabelecem, de certa forma, uma ponte entre a justeza procedimental e a eficácia policial (e do sistema de justiça). Nesse sentido, supomos que alguns aspectos procedimentais como o tratamento correto e equânime, a escuta e a resposta aos cidadãos - têm potencial de amplificar a capacidade de resolução dos crimes que chegam à polícia e ao ciclo da justiça criminal.

Tendo por base aspectos comumente ligados à maior ou menor propensão de abertura de inquérito e investigação efetiva dos crimes (conhecimento de autoria, flagrante, tipo de crime e desfecho), aventamos outros motivos que podem influenciar 
os trabalhos realizados pelas agências policiais. Para além da desconfiança nas agências de polícia e justiça, cidadáos cada vez mais receiam ter contato direto com a polícia (Adorno e Pasinato, 2010, p. 77). Não é de hoje que o registro de ocorrência policial é evitado, sobretudo quando se trata de crimes menos graves em que, no caso de serem patrimoniais, não há exigências de seguro. $\mathrm{O}$ descrédito das instituiçóes estaria levando também os cidadãos a não testemunharem sobre ocorrências ou não fornecerem quaisquer informaçóes adicionais para sua apuração, em um círculo vicioso que dificulta ainda mais a resolução dos casos.

Como estamos tratando da aplicação de teorias desenvolvidas em contextos significativamente distintos do cenário brasileiro, é necessário discutirmos as diferenças acerca do modelo policial do país. O Brasil possui uma organização policial que não encontra paralelo na maior parte dos países: aqui, a força policial de maior contingente - as corporaçóes estaduais - atua de forma bipartida. $\mathrm{O}$ trabalho responsável pela investigação e pelas práticas judiciárias é desempenhado pela polícia civil; o policiamento preventivo ou ostensivo cabe à polícia militar. Essa divisão acarreta uma infinidade de problemas (corporativismo, desavenças entre as forças, falta de comunicação, custos elevados para a sustentação de duas organizaçooes distintas, entre outros), dificultando sobremaneira a execução eficaz do policiamento. ${ }^{5}$

Sem desconsiderar a importância do significado desse estado de coisas, é importante observar que o tema da legitimidade é transversal às estruturas das instituiçóes do sistema de justiça e segurança pública. Ele diz respeito ao relacionamento entre os agentes públicos e os cidadãos e as possibilidades de aprimorar o exercício da autoridade de forma que esta seja mais eficaz do ponto de vista dos que exercem o poder e mais bem aceita e considerada justa e adequada por parte dos cidadãos. Embora também dependente das estruturas institucionais em que os poderes estão organizados, a dimensão da legitimidade que aqui estamos tratando guarda certa autonomia em relação a essas estruturas.

Apesar das evidências (que embora poucas, são consistentes) do alto nível de impunidade penal encontradas em algumas cidades brasileiras, dos índi- ces criminais e dos dados de pesquisas de vitimização que mostram o baixo nível de confiança que as pessoas têm sobre o cumprimento da lei e sobre a eficácia das instituiçôes (especialmente a polícia), ${ }^{6}$ não há, no cenário brasileiro, imagem empírica clara sobre a ligação entre esses aspectos.

\section{Açáo policial, confiança e legitimidade em São Paulo}

Neste artigo, o principal objetivo é testar, por meio da análise de um survey realizado na cidade de São Paulo, algumas dessas relaçóes estudadas nos contextos europeu e norte-americano nas últimas décadas. A principal delas incide sobre as açóes institucionais, a confiança e a legitimidade das instituições no município. As ações são analisadas a partir da visão dos entrevistados, sobretudo agentes, acerca do poder público, seja de forma direta ou indireta. Mais especificamente, estamos considerando fatores relacionados com a percepção sobre a eficácia e a conduta policial quanto à transparência, à capacidade de ouvir, levando em conta os relatos e o posicionamento de seus interlocutores, e ao bom senso na tomada de decisóes no sentido de estarem coerentes com as expectativas - todos eles ações da justeza procedimental.

Além das ações institucionais, estamos considerando também outros aspectos que podem ter impacto substantivo sobre a confiança e a legitimidade das instituiçóes, como a insegurança dos cidadãos, os abusos ou as ilegalidades cometidas por policiais, a vitimização criminal e fatores ligados às políticas públicas locais, por exemplo, problemas de iluminação pública, carros abandonados nas vias públicas, entre outros. ${ }^{7} \mathrm{Um}$ conjunto de variáveis socioeconômicas foi também incluído não só para o controle da análise, mas também para verificar a conexão entre as condiçôes sociais e as demais variáveis analisadas.

\section{Aspectos metodológicos}

O survey utilizado para a realização deste artigo é um instrumento desenvolvido pelo NEV-USP para uma pesquisa domiciliar sobre "atitudes, nor- 
mas culturais e valores sobre direitos humanos e violência", que ocorre a cada dois ou três anos desde 1999 em São Paulo e, alternadamente, também em outros municípios do país. Para este trabalho foi utilizada a versão de 2013 do survey, realizado somente em São Paulo com um total de 1001 entrevistados com 16 anos ou mais de idade, estratificados proporcionalmente por sexo e idade. Os entrevistados foram selecionados através de uma amostra probabilística realizada em dois estágios: por sorteio dos setores censitários, de forma proporcional ao tamanho dos distritos administrativos do município, e por sorteio dos domicílios nos setores selecionados.

O survey contém uma série de questóes relevantes para a análise de alguns dos tópicos focalizados nesta análise, de forma tanto a relacionar os diferentes aspectos abordados quanto a problematizar as análises que têm sido desenvolvidas no contexto internacional.

\section{Variáveis}

Inicialmente, selecionamos para a análise conjuntos de variáveis específicas:

- Variáveis de vitimização (ter sido vítima de determinadas ofensas em um determinado período): "desde que mora no bairro, alguém o(a) ameaçou com um revólver para roubar algo seu?"; "desde que mora no bairro, sofreu algum tipo de agressão física?"; ou "desde que mora no bairro, alguém o(a) ameaçou com uma faca para roubar algo seu?".

- Variáveis sobre a ação institucional (presença policial ou percepção/avaliação sobre açóes realizadas pelas polícias): "qual a propensão de a polícia atender prontamente aos chamados da comunidade?"; "qual a propensão de a polícia conseguir manter as ruas do bairro tranquilas?"; "qual a propensão de a polícia ser educada quando aborda pessoas nas ruas?"; "qual a propensão de quantidade/qualidade existente de policiamento?".

- Sobre a confiança na polícia: "De maneira geral, o quanto o(a) sr(a) acha que confia na polícia?”.

- Variáveis vinculadas a desvios/agressóes co- metidas por policiais: "desde que mora nesse bairro, algum policial ou autoridade o ameaçou para tirar-lhe algum dinheiro?"; "desde que mora nesse bairro, você sofreu algum tipo de agressão ou maus tratos por policiais?"; "os policiais protegem o tráfico de drogas?”.

- Variáveis de percepção de desordem urbana: "percepção de ausência de iluminação pública" e "percepção de carros abandonados".

- Percepção de segurança: "sente segurança ao andar sozinho à noite pela vizinhança?".

- Medida de "legitimidade das leis": "pessoas devem obedecer às leis mesmo quando acham que as leis não estão certas?" (uma das principais formas de mensurar a legitimidade das leis na literatura sobre justeza procedimental).

Além dessas variáveis, incluímos também na análise medidas de "moralidade individual" dos entrevistados, incluindo questóes que problematizam o quanto os cidadãos estariam dispostos a concordar com desvios das leis e das regras por parte dos agentes públicos em prol de resultados/puniçóes no campo da justiça e segurança: “O(a) sr(a) acha que é melhor deixar dez pessoas culpadas livres a errar condenando um inocente?" e "um policial pode bater em um preso que tenha tentado fugir?".

Do total dos respondentes do survey, 53,1\% são do sexo feminino e $46,9 \%$, do sexo masculino. Com relação à escolaridade da amostra, 40,4\% dos respondentes concluíram até o ensino fundamental, $39,1 \%$ afirmaram possuir ensino médio completo ou incompleto e $20,5 \%$ afirmaram possuir superior completo ou incompleto. Quanto à idade, 22,2\% são adolescentes e jovens de 16 a 25 anos, 24,5\% tem entre 26 e 35 anos, 20,3\%, entre 36 e 45 anos, $19,2 \%$, entre 46 e 60 anos e 13,8\% estão acima dos 60 anos de idade. Quanto à etnia/cor, 53,3\% se declararam "brancos" e 45,3\% "negros" (incluindo as categorias negro, mulato, pardo e moreno). As demais categorias relativas à etnia/cor da pele atingiram em conjunto $1,3 \%$ dos respondentes.

A análise de regressão logística foi realizada em duas etapas, com base em temas de interesse (uma etapa tendo como variável dependente a confiança policial e outra tendo como variável dependente a legitimidade). Para a realizaçáo desta análise, as diferentes 
variáveis foram transformadas em variáveis dicotômicas, unindo, por exemplo, categorias como "concordo muito" e "concordo pouco" e "discordo muito" e "discordo pouco", ou "sempre" e "quase sempre" e "nunca" e "quase nunca", e assim por diante, atribuindo-se os valores 1 e 0 para cada um dos agrupamentos da qual a variável passou a ser composta.

Nos modelos de regressão foram utilizadas como variáveis de controle apenas a idade e a escolaridade, sendo que as demais (sexo, etnia/cor da pele e classe) náo se mostraram estatisticamente significativas nem ajudaram a ajustar o modelo, e foram, por isso, excluídas da análise.

A ausência de significância estatística da variável relativa à etnia/cor da pele é um ponto que chama a atençáo, pois, como observado em não poucos estudos, principalmente norte-americanos (ver, por exemplo, Tyler e Fagan, 2008), a populaçáo negra tende a ter índices de desconfiança e baixa legitimidade nas instituiçóes policiais em proporção consideravelmente superior aos demais grupos. Analisando variáveis relativas à percepçáo sobre a ação policial presentes no survey (relativas a maus tratos ou agressão por policial e avaliaçáo sobre a celeridade do atendimento policial, entre outros itens), observamos que embora a percepção dos negros sobre a ação da polícia seja consideravelmente pior do que a dos não negros, $o$ mesmo não ocorre com relação à confiança na polícia e à legitimidade das leis, como destacamos (resultado similar, com relação à confiança, foi também encontrado por Oliveira Júnior, 2011). Uma hipótese para isso seria o fato de que essas populaçóes historicamente desfavorecidas já possuem uma expectativa mais baixa do que a da população em geral sobre a ação policial, e por isso as avaliaçóes acerca da confiança e da legitimidade poderiam mostrar-se similares entre brancos e não brancos, mesmo que os últimos recebam um tratamento menos igualitário, mais repressivo e mais violento que os primeiros. De certa forma, essa ideia já foi anteriormente destacada por Norris (2011), mas em situação distinta. Para o autor, a permanência de um regime democrático leva os cidadãos a se tornarem paulatinamente mais exigentes, reduzindo a confiança nas instituiçóes caso a sua performance não seja aperfeiçoada. Se as expectativas forem baixas, a confiança nas instituiçôes não se alterará caso elas apresentem uma performance mais baixa.

\section{Resultados}

Frequências das variáveis analisadas

Analisando as frequências dos dados levantados, vemos em primeiro lugar que o nível de confiança policial se revela consideravelmente baixo: apenas $10,4 \%$ do total afirmam "confiar muito" na polícia. A variável utilizada para medir a legitimidade em relaçáo às leis, por outro lado, demonstra uma aceitação maior por parte dos entrevistados. Quando indagados se deveriam seguir as leis mesmo não concordando com elas, 65,4\% apoiaram totalmente ou em parte.

Apesar da baixa confiança conferida às polícias, quando analisamos itens relativos à eficácia conferida a atuação policial no cumprimento de suas metas, há propensão a uma avaliação melhor, ainda que, se considerarmos os percentuais, não se possa dizer que tais índices representem uma aceitação das ações policiais. Para 58,2\% do total de entrevistados, por exemplo, a polícia sempre ou quase sempre responde imediatamente a um chamado; para $42,3 \%$, a polícia sempre ou quase sempre consegue manter as ruas tranquilas; e para $45,7 \%$, há "bastante policiamento" na regiāo em que moram.

Os índices de justeza procedimental também foram consideravelmente elevados no que concerne às variáveis "prestar atenção ao que o atendido disse" e "explicar as providências" que foram tomadas pelos policiais $(69,8 \%$ e $74,2 \%$ de respostas afirmativas, respectivamente). Os índices positivos são bem menores quando consideramos outros itens relacionados com as impressóes dos entrevistados sobre o comportamento dos policiais nos atendimentos: $39 \%$ consideraram que os policiais foram "muito educados"; $33,1 \%$, que foram "muito justos"; $52,8 \%$, que ficaram "muito satisfeitos" com o trabalho policial.

Do total da amostra, 57,2\% dos respondentes afirmaram sentir-se inseguros ou muito inseguros ao andarem sozinhos(as) à noite pela vizinhança. Com relação à vitimização sofrida pelos entrevistados no bairro em que moram, 15,4\% afirmaram já terem sido ameaçados por arma de fogo, 11,6\%, sofrido agressão física, $6,2 \%$, ameaçados com uma faca durante um roubo e 1,0\% (10 pessoas), já ter sido ferido por arma de fogo. 
A vitimização por parte de policiais, ainda que citada por parcelas pequenas dos entrevistados, também foi reportada: $6,4 \%$ do total afirmaram já terem sofrido algum tipo de agressão ou mau trato por policiais no bairro em que moram ${ }^{8}$ e $3,1 \%$, terem sido vítima de extorsão por policiais ou por uma autoridade. Além disso, para $43,2 \%$ dos respondentes, a polícia sempre ou quase sempre protege o tráfico de drogas.

Quanto à desordem física do bairro em que vivem, na percepção de $16,3 \%$ dos entrevistados a presença de carros abandonados é bastante frequente; $14,1 \%$ reportaram ausência de iluminação; $9,8 \%$, que há uma grande quantidade de lotes vazios/abandonados; e, de acordo com 8,7\%, são frequentes no bairro construçôes abandonadas.

Por fim, quanto aos itens relativos à moralidade individual, 54,7\% discordam totalmente ou em parte que é "melhor deixar dez pessoas culpadas livres a errar condenando um inocente"; 59,7\% concordam totalmente ou em parte que um policial pode bater em um preso que tenha tentado fugir; e $58,9 \%$ concordam totalmente ou em parte com a aplicaçáo da pena de morte ao menos para alguns tipos de crime. Esses números evidenciam a mentalidade punitivista presente em amplas parcelas da população, como outras pesquisas têm demonstrado. ${ }^{9}$

\section{Confiança na polícia}

A análise da relaçáo entre a confiança e a legitimidade com as demais variáveis elencadas foi realizada em duas etapas: primeiro, tomando a confiança na polícia como variável dependente; depois, fazendo o mesmo processo em relaçáo à legitimidade das leis. Foram mantidas nas regressōes as variáveis que se mostraram estatisticamente significativas no momento de entrada no modelo, ou aquelas que, embora náo fossem significativas, ajudaram a ajustar o modelo, impactando nas razóes de chance (odds-ratio - OR) das demais variáveis e/ou em sua significância. Em cada modelo são apresentadas as razôes de chance para cada variável e seu respectivo nível de significância.

Na primeira etapa, apresentada na Tabela 1 , há resultados importantes entre as variáveis analisadas, que se apresentam muito similares a outras análises realizadas no cenário internacional (Tyler e Jackson, 2013; Sunshine e Tyler, 2003; Tyler, 1990, entre outros). $\mathrm{O}$ fato de os policiais "serem educados" durante a ação policial, por exemplo, aumenta em catorze vezes a chance de haver confiança na polícia. Trata-se aqui, a priori, de uma variável vinculada ao tratamento correto dos agentes institucionais perante a populaçáo, um dos componentes das açóes de justeza procedimental. A capacidade dos policiais em manter as ruas tranquilas, que é um indicador de eficácia policial, por sua vez, aumenta em 2,5 vezes esta mesma chance.

A ameaça por parte de um policial ou de outra autoridade, apesar de náo ser significativa, ajudou a ajustar o modelo, aumentando a significância das demais variáveis. O mesmo ocorreu com a variável "ter sido vítima por arma de fogo no bairro onde mora”, e por essa razão as duas variáveis foram mantidas no modelo. As variáveis "escolaridade" e "idade" também alteraram consideravelmente as significâncias das variáveis (aumentando-as), ajudando assim a ajustar o modelo. Ambas são também estatisticamente significativas: cada ano a mais de escolaridade aumenta em 2,6 vezes a chance de se confiar na polícia, e cada ano a mais de vida aumenta essa chance em $1,1 \mathrm{vez}$.

\section{Tabela 1 \\ Razóes de Chance-OR das Variáveis Independentes para a Confiança na Polícia} (Sáo Paulo, 2013)

\begin{tabular}{lcc}
\cline { 2 - 3 } & OR & Sig. \\
\hline Policiais foram educados & 14,067 & ${ }^{* *}$ \\
\hline Polícia mantém ruas tranquilas & 2,487 & ${ }^{*}$ \\
\hline Ameaça por policial/autoridade & 2,306 & \\
\hline Ameaça por arma de fogo & 4,878 & \\
\hline Idade & 1,123 & ${ }^{* *}$ \\
\hline Escolaridade & 2,560 & ${ }^{* *}$ \\
\hline $\mathrm{N}$ & \multicolumn{2}{c}{1001} \\
\hline Pseudo $\mathrm{R}^{2}$ & \multicolumn{2}{c}{0,239} \\
\hline${ }^{*} \mathrm{p}<0,1 ;{ }^{* *} \mathrm{p}<0,05$. & \multicolumn{2}{c}{}
\end{tabular}

Fonte: NEV/USP (2013). 
Tabela 2

Razóes de Chance-OR das Variáveis Independentes para Confiança na Polícia (com Inclusáo da Variável "Pessoas Culpadas Livres $\times$ Condenar Inocente") (Sáo Paulo, 2013)

\begin{tabular}{|c|c|c|}
\hline & OR & Sig. \\
\hline Policiais foram educados & 17,056 & ** \\
\hline Polícia mantém ruas tranquilas & 14,226 & $* *$ \\
\hline Ameaça por policial/autoridade & 3,973 & \\
\hline Ameaça por arma de fogo & 9,208 & * \\
\hline Idade & 1,150 & $* *$ \\
\hline Escolaridade & 3,597 & $* *$ \\
\hline $\begin{array}{l}\text { Pessoas culpadas livres } \times \\
\text { condenar inocente }\end{array}$ & 25,289 & ** \\
\hline $\mathrm{N}$ & \multicolumn{2}{|c|}{1001} \\
\hline Pseudo $\mathrm{R}^{2}$ & \multicolumn{2}{|c|}{0,270} \\
\hline
\end{tabular}

Com relação a este primeiro modelo, controlado por escolaridade e idade, além das variáveis relativas à vitimização e a ameaças sofridas por policial ou outra autoridade, vemos que as principais variáveis de impacto sobre a confiança policial são um indicador relativo à justeza procedimental e outro, à eficácia policial, tendo o primeiro um impacto maior que o segundo.

Para além dessas variáveis analisadas com relação à confiança, alguns dados sobre as atitudes esperadas pela população com relação à polícia em algumas situaçōes específicas indicam que essas características de confiança, apoio e aprovação das entidades institucionais precisam levar em conta as percepções que a população possui em relação a temas como ação policial, uso da força e moralidade individual. Ao incluirmos variáveis relacionadas com esses temas ao modelo de regressão, a única mantida foi "melhor deixar dez pessoas culpadas livres a errar condenando um inocente". A Tabela 2 apresenta o primeiro modelo acrescido dessa variável.

Com efeito, a inclusão da variável modificou significativamente os coeficientes anteriormen- te observados. O fato de os policiais terem "sido educados" passou a representar um aumento de 17 vezes na chance de haver confiança na polícia. A capacidade de as polícias manterem as ruas tranquilas cresceu ainda mais, indo de 2,5 vezes para 14,2 vezes, o que mostra uma relação entre esta variável e a questão da moralidade individual acrescentada. A ameaça por arma de fogo passa a ser estatisticamente significativa (em nível de $\mathrm{p}<0,1$ ), com uma chance 9,2 vezes maior de haver confiança na polícia. A chance de haver confiança na polícia, por sua vez, é 25,3 vezes maior quando os indivíduos concordam com a frase correspondente à nova variável inclusa no modelo ("melhor deixar 10 pessoas culpadas livres a errar condenando um inocente").

\section{Legitimidade}

Em relação à legitimidade das leis ("pessoas devem obedecer às leis mesmo que não concordem com elas"), entretanto, encontramos diferenças importantes ao compararmos com a análise do modelo anterior. Neste modelo foram mantidas três variáveis que não constavam no modelo relativo à confiança policial: sensação de segurança ("sente seguro"), percepção sobre a quantidade de iluminação existente no bairro ("ausência de iluminação”) e percepção de má conduta policial ("policiais protegem tráfico"). Por outro lado, "já ter sofrido ameaça por policial ou autoridade" foi excluída do modelo.

A variável "policiais serem educados" no transcorrer da ação policial continua sendo um fator impactante, aumentando a chance de os entrevistados conferirem legitimidade às leis, assim como a variável "ameaça por arma de fogo", ao contrário do que acontece quando se apresentam as variáveis "policiais protegem tráfico" e "ausência de iluminação". A percepçáo de que os policiais protejam o tráfico faz com que a chance de haver crença na legitimidade seja quase quatro vezes menor $(0,277)$, enquanto para a variável "ausência de iluminação no bairro", a chance é três vezes menor $(0,3)$. Deve-se considerar também que a falta de iluminação em um bairro pode ser um sinal da existência de carências em políticas públicas de diversos tipos, fator que pressiona contra a legitimação das instituiçóes de uma forma geral. 
Tabela 3

Razóes de Chance-OR das Variáveis Independentes para Legitimidade das Leis (Sáo Paulo, 2013)

\begin{tabular}{|c|c|c|}
\hline & \\
\hline & OR & Sig. \\
\hline Policiais foram educados & 2,451 & $*$ \\
\hline Polícia mantém ruas tranquilas & 1,085 & \\
\hline Sente seguro & 1,539 & \\
\hline Ameaça por arma de fogo & 2,993 & * \\
\hline Idade & 0,971 & \\
\hline Escolaridade & 0,987 & \\
\hline Ausência de iluminação & 0,304 & $* *$ \\
\hline Policiais protegem tráfico & 0,277 & $* *$ \\
\hline $\mathrm{N}$ & \multicolumn{2}{|c|}{1001} \\
\hline Pseudo $\mathrm{R}^{2}$ & \multicolumn{2}{|c|}{0,16} \\
\hline
\end{tabular}

${ }^{*} \mathrm{p}<0,1 ;{ }^{* *} \mathrm{p}<0,05$.

Fonte: NEV/USP (2013).
Curiosamente, de todas as variáveis relativas à eficácia policial, apenas foi mantida no modelo a variável sobre a capacidade da polícia em "manter as ruas tranquilas", não porque era estatisticamente significativa, mas para fazer um ajusto no modelo. Em modelos anteriormente construídos por Tyler e outros pesquisadores, ainda que essa dimensão tenha apresentado impacto menor do que as variáveis de justeza procedimental, foi demonstrado que tais variáveis possuíam um impacto não desprezível, quando analisada a legitimidade da polícia.

Quando inserimos a variável relativa à culpabilização ou não de pessoas inocentes ("melhor deixar dez pessoas culpadas livres a errar condenando um inocente"), inversamente ao que ocorreu em relação à análise da confiança policial, além da nova variável inserida, apenas a variável "policiais protegem tráfico" permanece tendo impacto sobre a legitimidade.

\section{Discussáo e consideraçóes}

Utilizando-se de survey desenvolvido em 2013 em São Paulo, realizamos neste artigo uma incursão sobre o tema da legitimidade e da confiança institucional através da análise de um conjunto de variáveis frequentemente utilizadas no campo da justeza procedimental. Encontramos, com base na amostra estudada, relaçóes similares e diferenças importantes em relação a estudos realizados em outros países.

A análise apontou a existência de uma relação significativa entre as dimensões da justiça procedimental e a confiança institucional (na polícia), e, com menor força, entre as dimensões da eficácia policial e a confiança institucional. Com relação à variável que diz respeito à legitimidade das leis, encontramos duas associaçóes importantes entre legitimidade e variáveis relativas à ação policial, sendo uma delas diretamente ligada à justeza procedimental (policiais terem sido "educados" durante a ação), de forma similar aos achados das pesquisas realizadas nos contextos britânico e norte-americano (Tyler e Jackson, 2013; Sunshine e Tyler, 2003; Tyler, 1990; e outros), e outra relacionada à percepção de má conduta policial (policiais protegerem o tráfico).

Além delas, encontramos também uma associação significativa entre legitimidade e uma variá-

Fonte: NEV/USP (2013). 
vel relativa à vitimização pessoal (ter sido ameaçado por arma de fogo) e outra entre legitimidade e uma variável ligada à percepção de desordem física do bairro (ausência de iluminação). O fato de já ter sido ameaçado por arma de fogo está relacionado positivamente com a legitimidade, o que pode ocorrer, entre outras razóes, pelo medo e pela insegurança, que ampliam o apego às autoridades responsáveis pelas leis e pela segurança. A falta de iluminação, por sua vez, está associada negativamente à legitimidade, indicando a insatisfação ou o desamparo da população em relação às instituiçôes e às autoridades sobre problemas públicos de sua responsabilidade, ampliando a falta de reconhecimento de leis e autoridades.

A existência de cada um desses itens aumenta ou diminui, em diferentes proporçóes, a chance de que os cidadãos confiram legitimidade às leis. Quando se insere uma variável relacionada com a moralidade individual, por outro lado, a única variável que se mantém com impacto significativo sobre a legitimidade, além da própria variável relativa à moralidade individual, é aquela que concerne à percepção de que os policiais protegem atividades criminosas (no caso, o tráfico de drogas). Deve-se observar que esta última variável (tráfico) representa uma dimensão imersa, ela também, em forte "carga moral".

A presença dessa variável é algo que chama atenção. Tanto a confiança na polícia como a legitimidade das leis se ampliam conforme mais indivíduos afirmam serem favoráveis a uma política estatal que aja em detrimento dos direitos individuais. Em ambos os casos, sobretudo em relação à confiança, ela é a variável de maior impacto, ou seja, não obstante a influência de fatores como o tratamento que a polícia dá aos cidadãos - e também a eficácia da polícia na resolução de problemas ligados ao crime -, a confiança e a legitimidade são consideravelmente mais sensíveis ao campo dos valores que conformam a moralidade individual.

Além de termos encontrado uma relação entre confiança e eficácia da polícia de impacto quase táo relevante quanto a relação entre confiança e nossa variável relacionada com a justeza procedimental o que difere dos resultados das pesquisas realizadas sobre o tema no contexto internacional, em que a dimensão da justeza procedimental apresenta associação consideravelmente mais forte ${ }^{10}$, , outra diferença importante com essas pesquisas foi o fato de não termos encontrado nenhuma relação entre legitimidade das leis e a variável relativa à eficácia policial.

De toda forma, como dissemos no início, é necessário ter em mente as particularidades do cenário nacional e de suas instituições, que possuem características muito distintas às da maior parte dos contextos em que essas pesquisas têm sido realizadas. Ainda assim, a análise aqui empreendida mostrou consistência com as perspectivas teóricas de que partimos.

O fato de termos encontrado relações positivas entre uma variável concernente à justeza procedimental - tanto no que diz respeito à confiança institucional como no tocante à legitimidade das leis - é um dado relevante que aponta, ao menos preliminarmente, uma perspectiva promissora: a de que um melhor tratamento da população por parte da polícia pode ter impactos positivos sobre o elo entre a instituição e a população, o que pode ajudar a transformar algumas condutas e mentalidades institucionais existentes. Tal perspectiva, quem sabe, se consolide como um alento, sobretudo ao considerarmos as características das polícias brasileiras, marcadas por alto índice de letalidade, denúncias de má conduta e baixa confiança, e de uma população que, em grande medida, defende práticas policiais repressivas e ajustadas a uma cultura punitivista.

Para além dos resultados, é essencial continuar avançando nas formas de delinear e mensurar o conceito de legitimidade. Como observado em outros trabalhos voltados para analisar a relação entre legitimidade e atitudes das polícias, em especial os produzidos por Tyler e outros pesquisadores no campo da justeza procedimental, faz-se necessário avançar nas perspectivas de captação de atributos importantes que se relacionam à propensão dos indivíduos em obedecer as leis, como a convicção (ou não) em fazê-lo, o medo das possíveis consequências de não obedecer, o cinismo legal e o alinhamento moral dos indivíduos com as leis e as instituiçóes.

Do ponto de vista metodológico, para além dos trabalhos ancorados nas pesquisas de survey, estas 
análises também se beneficiariam da incorporação de outras estratégias, bem como do desenvolvimento de inovaçôes para a produção de conhecimento sobre os temas em foco. Nesse sentido, a utilização de pesquisas longitudinais, e também de entrevistas em profundidade, pode trazer importantes resultados para o estudo da confiança e da legitimidade ao aprofundar a relaçáo e o impacto entre as diferentes dimensōes estudadas.

É fundamental levar em conta a influência de questóes contemporâneas no campo da justiça e da segurança, pois trazem desafios relevantes para o futuro. Entre elas, como apontado por Loader e Sparks (2013), encontram-se as transformaçôes no campo da governança, com a participaçáo cada vez maior de forças externas aos governos no âmbito da gestão de políticas públicas. Além disso, há o fenômeno da transnacionalização do crime e a influência cada vez maior das novas estratégias e tecnologias de segurança que desafiam as autoridades públicas e transformam as "regras do jogo", ao mesmo tempo que, paradoxalmente, dialogam como atores fortes no setor, trazendo mudanças e inovaçóes nas práticas de segurança.

Essas questôes, portanto, não se esgotam aqui, mas configuram um terreno fértil para novas investigações em diferentes contextos.

\section{Notas}

1 Ver a análise desenvolvida por Lipsky (1980) acerca dos "burocratas de nível de rua".

2 Sobre essas críticas, ver, por exemplo, Nivette e Eisner (2013), Loader e Sparks (2013), Hough, Jackson e Bradford (2013) e Tankebe e Liebling (2013), entre outros.

3 Em 2015, ocorreram no país 3.345 mortes por policiais civis e militares, de acordo com o Anuário Brasileiro de Segurança Pública 2016, o que confere ao país, proporcionalmente, o maior número de mortos por policiais no mundo.

4 Como enfatizado em um recente relatório institucional do Núcleo de Estudos da Violência da Universidade de São Paulo, "numerosos investigadores [...] afirmaram que este aspecto do seu desempenho tem mais importância do que as taxas de depuração e as taxas de criminalidade quando se trata de avaliação dos cidadãos da sua força policial" (NEV/USP, 2013, p. 67).
5 Há uma considerável literatura que trabalha com essa problemática, como os trabalhos de Sapori (2016), Souza e Battibugli (2014), Lima et al. (2014), Azevedo (2013), Teixeira (2013), Sapori e Andrade (2013), Santos Jr. et al. (2011), Zaluar (2007), Muniz e Musumeci (2000) e Adorno (1998).

6 Não são poucas as pesquisas que têm mostrado, seja no cenário nacional, seja em cidades ou estados específicos, a baixa confiança institucional que incide, sobretudo, nas instituiçóes de justiça e segurança. Ver, por exemplo, pesquisas realizadas por institutos de pesquisa como o Ibope, a Confederaçáo Nacional de Transportes (CNT) e os Indicadores de Referência de Bem-estar no Município (Irbem). Curiosamente, algumas medições, como o Índice de Percepção do Cumprimento da Lei (IPCL) da Escola de Direito da Fundação Getúlio Vargas, realizado em 2013, têm demonstrado que, se por um lado é frequente encontrar no país esse quadro de descrença nas leis e nas instituiçôes, por outro, os cidadáos parecem ser muito mais tolerantes em relação a suas próprias atitudes diante das normas sociais, do que se mostram quando as regras valem para os outros.

7 A percepção de desordem urbana é um importante fator relacionado com a percepção de insegurança e a localização espacial das práticas criminais, como já identificado por alguns estudos. Ver, sobretudo, os trabalhos vinculados à broken windows theory (Wilson e Kelling, 1982).

8 Mesmo em se tratando de pesquisas de vitimização, em que os questionários são respondidos em domicílio e os entrevistadores têm garantia de sigilo de qualquer informação que possa identificá-los, deve-se considerar que pode haver subnotificação das ocorrências por parte dos entrevistados, sobretudo em questôes mais delicadas como a violência policial.

9 Pesquisa realizada pelo Fórum Brasileiro de Segurança Pública (2015, p. 108) demonstrou, por exemplo, que metade da população das capitais brasileiras acredita que "bandido bom é bandido morto".

10 Com relação a este ponto deve-se guardar certa cautela, pois, como destacamos, apesar de a legitimidade e a confiança possuírem intersecções importantes, elas não representam a mesma dimensáo, e os estudos no cenário internacional têm sido feitos, em geral, acerca da dimensão da legitimidade, não se devendo, portanto, esperar encontrar necessariamente resultados similares nas associaçôes entre essas duas dimensões e os demais fatores analisados. 


\section{BIBLIOGRAFIA}

ADORNO, Sérgio. (1998), "Consolidação democrática e políticas de segurança pública no Brasil: rupturas e continuidades", in Jorge Zaverucha (org.), Democracia e instituiçôes políticas brasileiras no final do século XX. Recife, Bagaço. ADORNO, Sérgio \& PASINATO, Wânia. (2007), "A justiça no tempo, o tempo da justiça". Tempo Social, 19 (2): 131-155.

$\&$ (2010), "Violência e impunidade penal: da criminalidade detectada à criminalidade investigada". Dilemas: Revista de Estudos de Conflito e Controle Social, 3 (7): 51-84.

ALENCASTRO, Luiz Felipe de. (1997). "Vida privada e ordem privada no Império", in Fernando A. Novais (dir.), História da vida privada no Brasil. Vol. 2: Luiz Felipe de Alencastro (org.), Império: a corte e a modernidade nacional, São Paulo, Companhia das Letras.

AZEVEDO, Rodrigo Ghiringheli de. (2013), "Elementos para modernização das polícias do Brasil”. Revista Brasileira de Segurança Pública, 10: 8-20, suplemento especial.

BECKER, Gary. (1968), "Crime and punishment: an economic approach". The Journal of Political Economy, 76 (2): 169-217.

BEETHAM, David. (1991), The legitimation of power. Londres, Macmillan.

BOTTOMS, Anthony \& TANKEBE, Justice. (2012), "Beyond procedural justice: a dialogic approach to legitimacy in criminal justice". The Journal of Crim. Law \& Criminology, 102: 119-170.

BRADFORD, Ben \& QUINTON, Paul. (2014), "Self-legitimacy, police culture and support for democratic policing in an English constabulary”. British Journal of Criminology, 54 (6): 1-24.

CARDIA, Nancy. (2012). Pesquisa nacional, por amostragem domiciliar, sobre atitudes, normas culturais e valores em relação à violação de direitos humanos e violência: Um estudo em 11 capitais de estado. São Paulo, Núcleo de Estudos da Violência da Universidade de São Paulo.

CHEVIGNY, Paul. (2000), "Definindo o papel das polícias na América Latina”, in Juan E. Méndez, Guillermo O’Donnel e Paul Sérgio
Pinheiro (orgs.), Democracia, violência e injustiça. São Paulo, Paz e Terra.

COICAUD, Jean-Marc. (2002), Legitimacy and politics. Cambridge, Cambridge University Press.

COLEMAN, James S. (1988), "Social capital in the creation of human capital". American Journal of Sociology, 94: 95-120.

COSTA, Emília Viotti da. ([1966] 1999). Da senzala à colônia. 7. ed. São Paulo, Editora da Unesp.

EISNER, M. (2001), “Modernization, self-control and lethal violence: the long-term dynamics of European homicide rates in theoretical perspective". British Journal of Criminology, 41 (4): 618-648.

EHRLICH, Isaac. (1996), "Crime, punishment and the market for offenses". Journal of Economic Perspectives, 10 (1). 43-67.

EHRLICH, Isaac \& BECKER, Gary. (1972), "Market insurance, self-insurance and self-protection". Journal of Political Economy, 80 (4). 623-648.

FAGAN, J. \& PIQUERO, A. (2007), "Rational choice and developmental influences on recidivism among adolescent felony offenders". Journal of Empirical Legal Studies, 4 (4). 715-748.

FÓRUM BRASILEIRO DE SEGURANÇA PÚBLICA. (2016), Anuário Brasileiro de Segurança Pública. São Paulo, Fórum Brasileiro de Segurança Pública.

GRANOVETER, Mark. (1985), "Economic action and social structure: the problem of embeddedness". The American Journal of Sociology, 91 (3): 481-510.

HOUGH, Mike; JACKSON, Jonathan \& BRADFORD, Ben. (2013), "Legitimacy, justice and compliance: an empirical test of procedural justice theory using the European social survey", in Justice Tankebe e Alison Liebling (orgs.), Legitimacy and criminal justice, Oxford, Oxford University Press.

IANNI, Octávio. ([1962] 1988). As metamorfoses do escravo. 2 ed. São Paulo/Curitiba, Hucitec/ Editora da UFRP.

JACKSON, Jonathan et al. (2012), "Policing by consent: understanding the dynamics of police power and legitimacy". ESS Country Specific Topline Results Series, 1, European Commission. 
LAFREE, G. D. (1998), Loosing legitimacy; street crime and the decline of social institutions in America. Boulder, Westview.

LIMA, Renato Sérgio de, BUENO, Samira \& SANTOS, Thandara. (2014), Opiniáo dos Policiais Brasileiros sobre Reformas e Modernização da Segurança Pública. São Paulo, Centro de Pesquisas Jurídicas Aplicadas (CPJA)/Escola de Direito da FGV/Fórum Brasileiro de Segurança Pública.

LIPSKY, Michael. (1980), Street level bureaucracy: dilemmas of the individual in the public services. Nova York, Russel Sage Foundations.

LOADER, Ian \& SPARKS, Richard. (2013), "Unfinished business: legitimacy, crime control and democratic politics", in Justice Tankebe e Alison Liebling (orgs.), Legitimacy and criminal justice, Oxford, Oxford University Press.

LOPES, Cléber da Silva. (2008), "Por que os brasileiros desconfiam da polícia?”, in José Álvaro Moisés e Rachel Meneghello (orgs.), A desconfiança politica e seus impactos na qualidade da democracia, São Paulo, Edusp.

MOISÉS, José Álvaro. (2008), "Cultura política, instituiçóes e democracia: liçóes da experiência brasileira". Revista Brasileira de Ciências Sociais, 23 (66): 11-43.

MOISÉS, José Álvaro e CARNEIRO, Gabriela P. (2008). "Democracia, desconfiança política e insatisfação com o regime - o caso do Brasil”. Revista Opinião Pública, 14 (1).

MUNIZ, Jaqueline e MUSUMECI, Leonarda. (2000). "As instituições de segurança pública do Estado do Rio de Janeiro", in Carlos Lessa (org), Reforma do Estado e proteçáo social: Os setores de saúde e segurança públicas no Rio de Janeiro. Rio de Janeiro: Editora UFRJ.

NEWTON, Ken (1999). "Social and Political Trust in Established Societies", in P. Norris (org.), Critical citizens: global support for democratic governance. Oxford, Oxford University Press.

NIVETTE, A. E., \& EISNER, M (2013). “Do legitimate polities have fewer homicides? A cross-national analysis". Homicide Studies, 17(1), 3-26.
NORRIS, Pippa. (2011). Democratic deficit: critical citizens revisited. Cambridge, Cambridge University Press.

NÚCLEO DE ESTUDOS DA VIOLÊNCIA DA UNIVERSIDADE DE SÁO PAULO (NEV/USP). (2013), 12th Report of the Center for the Study of Violence - University of Sáo Paulo. São Paulo, NEV/USP (institutional report). Disponível em http://www.nevusp.org/downloads/down273.pdf.

OLIVEIRA JÚNIOR, Almir de. (2011), “Dá para confiar nas polícias? Confiança e percepção social da polícia no Brasil”. Revista Brasileira de Segurança Pública, 5 (9). 6-22.

PINHEIRO, Paulo Sérgio. (1991), "Autoritarismo e transição". Revista USP, 9: 45-56.

(1997). "Violência, crime e sistemas policiais em países de novas democracias". Tempo Social, 9 (1): 43-52.

PUTNAN, Robert. D. (1996), Comunidade e democracia: a experiência da Itália moderna. Rio de Janeiro, FGV.

RIBEIRO, Darcy. (1996), O povo brasileiro: a formação e o sentido do Brasil. 2 ed. São Paulo, Companhia Das Letras.

RIBEIRO, Ludmila \& SILVA, Klarissa. (2010), "Fluxo do sistema de justiça criminal brasileiro: um balanço da literatura". Cadernos de Segurança Pública, 2 (1): 15-26.

ROTH, R (2009). American homicide. Cambridge, MA: Belknap Press: 14-28.

SAMPSON, R. J. \& BARTUSCH, D. J (1998), "Legal cynicism and (subcultural?) tolerance of deviance: the neighborhood context of racial differences”. Law \& Society Review, 32 (4): 777-804.

SANTOS JÚNIOR, Aldo Antonio dos; FORMEHL, Kelly Cristina \& PICCOLI, Daniela Lain. (2011), "O ciclo completo de polícia no Brasil". Revista de Antropologia Experimental, 11: 1-10.

SAPORI, Luis Flávio. (2016), "Como implantar o ciclo completo de polícia no Brasil?”. Revista Brasileira de Segurança Pública, 10: 50-58, suplemento especial.

SAPORI, Luis Flávio \& ANDRADE, Scheilla C. (2013), "Desafios da governança do sistema 
policial no Brasil: o caso da política de integração das polícias em Minas Gerais”. Revista Brasileira de Segurança Pública, 7 (1): 102-130. SILVA, Geélison F. \& BEATO, Cláudio. (2013), "Confiança na polícia em Minas Gerais: o efeito da percepção de eficiência e do contato individual”. Revista Opiniāo Pública, 19 (1): 118-153.

SOARES, Gláucio. (2000), "Quem tem medo da PM? A confiança na polícia militar do Distrito Federal e suas relaçóes com variáveis estruturais, demográficas e a experiência com a violência”. Revista Brasileira de Ciências Criminais, 32 (8): 269-277.

. (2013), "Confiança na polícia: uma perspectiva interativa”. Em Debate, 5 (5): 17-22.

SOUZA, Luís Antonio Francisco de \& BATTIBUGLI, Thaís. (2014), "O difícil caminho da reforma: a polícia e os limites do processo de reforma pós-redemocratização". Dilemas: Revista de Estudos de Conflito e Controle Social, 7 (2): 293-319.

SUNSHINE, J. \& TYLER, T. R. (2003), "The role of procedural justice and legitimacy in shaping public support for policing". Law \& Society Review, 37 (3): 513-548.

TANKEBE, Justice. (2009), "Public cooperation with the police in Ghana: Does procedural fairness matter?”. Criminology, 47 (4): 1265-1293. (2013). "Viewing things differently: the dimensions of public perceptions of police legitimacy”. Criminology, 51 (1): 103-135.

TANKEBE, Justice. \& Liebling, Alison (orgs.), Legitimacy and criminal justice. Oxford, Oxford University Press.

TEIXEIRA, Nilo. (2013), "A política de integração de Minas Gerais: a 'dependência de trajetória' na consolidação da política brasileira de segurança pública”. Dilemas: Revista de Estudos de Conflito e Controle Social, 6 (3): 369-410.

TYLER, Tom R. (1990), Why people obey the law. New Haven, Yale University Press.

TYLER, Tom R. \& FAGAN, Jeffrey. (2008), "Legitimacy and cooperation: Why do people help the police fight crime in their communities?”. Ohio State Journal of Criminal Law, 6: 231-275.
TYLER, Tom R. \& JACKSON, Jonathan. (2013), "Future challenges in the study of legitimacy and criminal justice", in Justice Tankebe e Alison Liebling (orgs.), Legitimacy and criminal justice, Oxford, Oxford University Press.

WEBER, Max. (1968), "Basic sociological terms", in __ Economy and society. Eds. G. Roth e C. Wittich. Berkeley, University of California Press.

WILSON, James Q. \& KELLING, George L. (1982), "Broken windows". The Atlantic Monthly, 249 (3). 29-38.

ZALUAR, Alba. (2007), "Democratização inacabada: fracasso da segurança pública”. Estudos Avançados, 21 (61): 31-49.

ZANETIC, André; NATAL, Ariadne L.; MANSO, Bruno P. \& OLIVEIRA, Thiago. (2016), "Legitimidade da polícia: segurança pública para além da dissuasão". Civitas: Revista de Ciências Sociais, 16 (4): 148-173.

ZMERLI, Sonja \& NEWTON, Ken. (2006), "Social trust and attitudes towards democracy: a close association after all?". Trabalho apresentado em ESRC Research Methods Festival. Oxford, St. Catherine's College. 


\section{AÇĀO INSTITUCIONAL, CONFIANÇA NA POLÍCIA E LEGITIMIDADE EM SÃO PAULO}

\section{André Zanetic}

Palavras chave: Confiança; Legitimidade; Ação institucional; Polícia; Justeza Procedimental.

O artigo apresenta uma investigação sobre os determinantes da confiança nas polícias e da legitimidade nas leis, baseada em um survey realizado em 2013 na cidade de São Paulo. A análise testa hipóteses presentes no cenário internacional, que sugerem que a percepção de determinadas condutas institucionais realizadas pelos agentes públicos, chamadas de justeza procedimental (procedural justice) tem mais impacto no processo de legitimação das polícias que os fatores relacionados com a eficácia policial. Os resultados corroboram parcialmente essa perspectiva destacando uma associação significativa entre confiança institucional e as variáveis relativas às dimensóes da justeza procedimental e da eficácia policial. Ressaltam também a associação da legitimidade das leis com a dimensão da justeza procedimental, em menor grau que o observado em relação à confiança.

\section{INSTITUIONAL ACTION, TRUST IN THE POLICE, AND LEGITIMACY IN SÁO PAULO}

André Zanetic

Keywords: Trust; Legitimacy; Institutional action; Police; Procedural justice.

This article presents an investigation about the determinants of trust in the police forces and in the legitimacy of laws. It is based on a survey held in the São Paulo City, in 2013. The analysis tests a few hypotheses that are present in the international scenario and preconize that the perception of certain institutionalized conducts performed by the police officers, which are referred to as procedural justice (such as respect, clarity about decisions taken, and the ability to listen), has greater impact in the legitimization process of police forces than factors related to police efficacy. The survey results, which partially corroborate with the findings in the international literature, highlighting a significant association between institutional trust and the variables related to the dimensions of procedural justice and police efficacy. The results also indicate the association between the legitimacy of laws and the scope of procedural justice to a lower degree than that observed in relation to trust.

\section{ACTION INSTITUTIONNELLE, CONFIANCE DANS LA POLICE ET LÉGITIMITÉ À SÁO PAULO}

André Zanetic

Keywords: Confiance; Légitimité; Action institutionnelle; Police; Justesse procédurale.

L'article présente une recherche sur les déterminants de confiance dans les polices et la légitimité des lois. Cette recherche a été développée à partir d'un sondage effectué en 2013 dans la ville de São Paulo. L'analyse teste des hypothèses présentes sur la scène internationale, qui suggèrent que la perception de certains comportements institutionnels d'agents publics, appelées justesse procédurale (procedural justice) a plus d'impact sur le processus de légitimation de la police que les facteurs liés à l'efficacité de la police. Les résultats corroborent en partie ce point de vue en mettant en évidence une association significative entre la confiance institutionnelle et des variables relatives aux dimensions de la justesse procédurale et de l'efficacité de la police. Ils mettent également en évidence, mais en moindre mesure que ce qui a été observé par rapport à la confiance, l'association de la légitimité des lois avec la dimension de la justesse procédurale. 